\title{
Biodegradation of Unpretreated Low-Density Polyethylene (LDPE) by Stenotrophomonas sp. and Achromobacter sp., Isolated From Waste Dumpsite and Drilling Fluid
}

\author{
Anindya Sundar Dey, Himadri Bose, Balaram Mohapatra and Pinaki Sar* \\ Department of Biotechnology, Indian Institute of Technology Kharagpur, Kharagpur, India
}

OPEN ACCESS

Edited by:

Datta Madamwar,

Sardar Patel University, India

Reviewed by:

Maria Fátima Carvalho,

Interdisciplinary Centre of Marine and Environmental Research,

University of Porto, Portugal Shaohua Chen, South China Agricultural University,

China

Santosh Kr Karn,

Sardar Bhagwan Singh Post Graduate Institute of Biomedical

Science \& Research, India

*Correspondence:

Pinaki Sar

sarpinaki@yahoo.com; psar@bt.iitkgp.ac.in

Specialty section:

This article was submitted to

Microbiotechnology,

a section of the journal

Frontiers in Microbiology

Received: 05 September 2020 Accepted: 13 November 2020 Published: 16 December 2020

Citation:

Dey AS, Bose H, Mohapatra B and Sar P (2020) Biodegradation of Unpretreated Low-Density

Polyethylene (LDPE) by

Stenotrophomonas sp. and Achromobacter sp., Isolated From Waste Dumpsite and Drilling Fluid. Front. Microbiol. 11:603210. doi: 10.3389/fmicb.2020.603210
Exploring the catabolic repertoire of natural bacteria for biodegradation of plastics is one of the priority areas of biotechnology research. Low Density Polyethylene (LDPE) is recalcitrant and poses serious threats to our environment. The present study explored the LDPE biodegradation potential of aerobic bacteria enriched from municipal waste dumpsite and bentonite based drilling fluids from a deep subsurface drilling operation. Considerable bacterial growth coupled with significant weight loss of the LDPE beads ( $8 \%)$, change in $\mathrm{pH}$ to acidic condition and biofilm cell growth around the beads (CFU count $10^{5}-10^{6} / \mathrm{cm}^{2}$ ) were noted for two samples (P and DF2). The enriched microbial consortia thus obtained displayed high (65-90\%) cell surface hydrophobicity, confirming their potential toward LDPE adhesion as well as biofilm formation. Two LDPE degrading bacterial strains affiliated to Stenotrophomonas sp. and Achromobacter sp. were isolated as pure culture from P and DF2 enrichments. 16S rRNA gene sequences of these isolates indicated their taxonomic novelty. Further biodegradation studies provided strong evidence toward the LDPE metabolizing ability of these two organisms. Atomic Fore Microscopy (AFM) and Scanning Electron Microscopy (SEM) revealed considerable damage (in terms of formation of cracks, grooves, etc.) on the micrometric surface of the LDPE film. Analysis of the average roughness $(R a)$, root mean square roughness $(R q)$, average height $(\mathrm{Rz})$, maximum peak height $(\mathrm{Rp})$, and maximum valley depth (Rv) (nanoroughness parameters) through AFM indicated 2-3 fold increase in nano-roughness of the LDPE film. FTIR analysis suggested incorporation of alkoxy $\left(1000-1090 \mathrm{~cm}^{-1}\right)$, acyl $\left(1220 \mathrm{~cm}^{-1}\right)$, nitro $\left(1500-1600 \mathrm{~cm}^{-1}\right)$, carbonyl $\left(1720 \mathrm{~cm}^{-1}\right)$ groups into the carbon backbone, formation of $\mathrm{N}-\mathrm{O}$ stretching $\left(1360 \mathrm{~cm}^{-1}\right)$ and chain scission $\left(905 \mathrm{~cm}^{-1}\right)$ in the microbially treated LDPEs. Increase in carbonyl index (15-20 fold), double bond index (1.5-2 fold) and terminal double bond index (30-40 fold) confirmed that biodegraded LDPEs had undergone oxidation, vinylene formation and chain scission. The data suggested that oxidation and dehydrogenation could be the key steps allowing formation of low molecular weight products suitable for their further mineralization by the test bacteria. The study highlighted LDPE degrading ability of natural bacteria and provided the opportunity for their development in plastic remediation process.

Keywords: LDPE, biodegradation, Stenotrophomonas, Achromobacter, bioremediation 


\section{INTRODUCTION}

Despite being a severe threat to the environment, plastic has become a very fundamental part of human society (Danso et al., 2019). It is widely used in various fields ranging from industries, agriculture to our day to day life, due to its lightness, durability, inertness and cheapness, etc., (Orr et al., 2004; Sudhakar et al., 2008; Yuan et al., 2020). Plastics are polymers of small aliphatic (for example polyethylene is made of $\left[\mathrm{CH}_{2}-\right.$ $\mathrm{CH}_{2}$ ] monomer) or aromatic molecules (e.g., polystyrene is a polymer of styrene) and their derivatives (such as polyvinyl chloride made from vinyl chloride monomer) (Andrady and Neal, 2009; Yang et al., 2014). Almost 6.3 billion tons of plastics were produced worldwide in 2015 and the number is increasing exponentially each year because of its efficient and versatile use (Yuan et al., 2020). Although plastics bring ease to our daily life, their uncontrolled use and careless disposal have been imposing a constant threat to the ecosystem, since they don't get degraded naturally even after many years and interfere with various natural and engineered processes adversely (Albertsson and Karlsson, 1990; Tokiwa et al., 2009; Raddadi and Fava, 2019). Non/slow biodegradation of plastics has led to their accumulation in the environment, thus causing wide spread pollution and harming marine as well as terrestrial life forms (Raddadi and Fava, 2019; Li et al., 2020). Plastics not only cause flooding by blocking the water draining system, but also get incorporated into the food chain of animals and damage their digestive system (Teuten et al., 2009; Muhonja et al., 2018). Long term accumulation of plastics in soil even changes its microbial community structure (Harshvardhan and Jha, 2013; Huang et al., 2019; Fei et al., 2020). Although, the amount of plastic wastes is reduced by incineration, it leads to secondary pollution due to the production of air pollutants like carbon monoxide, nitrogen oxides, etc., (Ru et al., 2020). The weathering and breaking down of plastic produce microplastics (MP) which migrate toward rivers, ponds, lakes, oceans and agricultural fields and affect them adversely (Yuan et al., 2020). Most of the commercially used plastics like polyethylene (PE) (low density, i.e., LDPE and high density or HDPE), polypropylene, polystyrene, polyvinyl chloride (PVC), polyamide (PA), polyethylene terephthalate (PET) are usually resistant toward biodegradation (Tokiwa et al., 2009; Danso et al., 2019). Their biodegradability is generally hindered due to several factors such as, (1) not being able to enter the microbial cell because of high molecular weight, (2) better stability in chemical structure, (3) absence of functional groups where microbial enzymes can attack and (4) high hydrophobicity and degree of crystallinity due to large carbon backbone (Tokiwa et al., 2009; Yang et al., 2014). Environmental toxicity, largescale accumulation and persistence of plastics warrant immediate action on development of efficient and ecofriendly methods for their degradation and exploration of microbial catabolic potential toward biodegradation of plastics (Montazer et al., 2018; Danso et al., 2019).

It has been found that the most common plastic, e.g., polyethylene (PE) can be subjected to microbial degradation if it is made with added pro-oxidants (generally transition metals) (Lee et al., 1991; Bonhomme et al., 2003). It has been observed that microbial growth and thus degradation of PE can be facilitated by several pretreatments like photooxidation (by exposing under UV irradiation), heat treatment (heating with high temperature) or chemical treatment (using acid). These pretreatments usually reduce the hydrophobicity by incorporating various functional groups (carbonyl, keto, nitro, etc.) into the inert carbon backbone (Albertsson et al., 1987; Orr et al., 2004; Hadad et al., 2005). The complex process of complete biodegradation of polyethylene follows these steps: (a) fragmentation by microbial intervention (adhering to the surface of polyethylene) or environmental components and incorporation of functional groups if applicable; (b) breaking down of polymer into oligomers or monomers as well as fatty acids, ketons, aldehydes, alcohols, etc., by enzymatic attack and free radicals; (c) uptake of these small products inside the microbial cells; (d) utilization of those molecules in cellular metabolism and finally production of $\mathrm{CO}_{2}, \mathrm{~N}_{2}$, $\mathrm{CH}_{4}, \mathrm{H}_{2} \mathrm{O}$, etc., (Yang et al., 2014; Wilkes and Aristilde, 2017; Muhonja et al., 2018; Delacuvellerie et al., 2019; Park and Kim, 2019). Both culture-based and culture-independent metagenomic studies have highlighted the PE (LDPE or HDPE) biodegradation abilities of several bacterial taxa viz. Enterobacter, Bacillus (Yang et al., 2014); Brevibacillus (Hadad et al., 2005); Pseudomonas (Muhonja et al., 2018); Alcanivorax, Ideonella, Marinobacter, Arenibacter (Delacuvellerie et al., 2019); Aneurinibacillus (Raddadi and Fava, 2019); Chelatococcus (Yoon et al., 2012); Achromobacter (Kowalczyk et al., 2016); Comamonas, Stenotrophomonas and Delftia (Peixoto et al., 2017). Besides, several members of soil-inhabiting Actinobacteria (Rhodococcus sp., Streptomyces coelicoflavus, Streptomyces KU1, KU5, KU6, KU8, Streptomyces werraensis, Streptomyces humidus, Streptomyces parvullus, Streptomyces aburaviensis, Amycolatopsis sp. HT-32, Nocardia sp. Saccharothrix wayandensis, etc.) have shown either weight reduction or partial degradation of PE films (Sivan et al., 2006; Abraham et al., 2017; Huang et al., 2019; Soulenthone et al., 2020). Among the fungal species, members of Aspergillus (Muhonja et al., 2018); Fusarium (Sivan, 2011); Penicillium, Zalerion (Raddadi and Fava, 2019); Chaetomium and Pullularia (Sudhakar et al., 2008) are well known for biodegradation of LDPEs and HDPEs. Microbial enzymes playing important role in biodegradation of $\mathrm{PE}$ are identified to be proteases, lipases, cutinases, laccases, manganese peroxidases, lignin peroxidases, alkane hydroxylases, etc., (Tokiwa et al., 2009; Bhardwaj et al., 2013; Wei and Zimmermann, 2017; Ahmed et al., 2018). Most of the prior studies have been done to assess the biodegradation of pretreated PEs. It is also observed that LDPE biodegradation takes place in a very slow manner even after the pretreatment (Sivan, 2011). In comparison to these studies, biodegradation of un-pretreated LDPE is not yet well studied. Identification and characterization of microbial enzymes and their molecular mechanisms have been considered to be critical in order to develop biotechnological process for plastic remediation (Danso et al., 2019).

The present study was conducted as a first step toward development of microbial plastic bioremediation through evaluating the potential of natural microbial communities and 
isolating suitable bacterial strains with desirable biocatalytic abilities. LDPE biodegradation potential of naturally occurring aerobic microorganisms (present in municipal waste dump site soil and bentonite based drilling fluids used during deep drilling of igneous crust of Deccan Traps, India) was evaluated by using enrichment culture technique. Degradation of LDPE by the enriched microorganisms was evaluated through a number of analytical techniques including examining the weight loss (of LDPE), change in its surface morphology (SEM and AFM) and chemical modification (FTIR). Two selected bacterial strains isolated from these enrichments were further studied for their individual ability of LDPE biodegradation. These strains were identified through 16S rRNA gene sequencing.

\section{MATERIALS AND METHODS}

\section{PE Materials, Samples for Microbiological Isolation, Media and Growth Conditions}

Two low-density polyethylene (PE) materials were used in this study as the carbon source: (a) Low Density Polyethylene beads (LDPE beads) (Sigma-Aldrich, United States) (b) Low Density Polyethylene plastic films (LDPE plastic films) (Ranco Poly Bags, Haryana, India). Before use, LDPE beads and films were surface sterilized by washing with $70 \%$ ethanol and followed by exposing them to UV rays for $15 \mathrm{~min}$.

Two types of environmental samples were used as the source of LDPE degrading microorganisms: (1) waste plastic sample from landfill soil and (2) drilling fluid. Waste plastic samples were collected from the local landfill site (designated as $\mathrm{P}$ ) inside the IIT Kharagpur campus $\left(22^{\circ} 18^{\prime} 45.3^{\prime \prime} \mathrm{N} \mathrm{87^{ \circ }} 19^{\prime}\right.$ 28.1" E). The drilling fluid (designated as DF2, DF4, DF7) samples were collected during a $3 \mathrm{~km}$ deep pilot borehole (KFD1) drilling in the Koyna region ( $\left.17^{\circ} 24^{\prime} 6^{\prime \prime} \mathrm{N} 73^{\circ} 45^{\prime} 8^{\prime \prime} \mathrm{E}\right)$ of the Deccan Traps, Maharashtra under the pilot phase of the Koyna scientific drilling project (Bose et al., 2020; Roy and Bansal, 2020). The various depths were as follows: DF2: 1901.255 mbs; DF4:2335.62 mbs; DF7: 2908.52 mbs (mbs: meters below surface). Samples were collected in sterile autoclaved bags with the help of sterile equipment. The DF samples were kept at $4{ }^{\circ} \mathrm{C}$ during transportation to lab and thereafter they were transferred to $-80{ }^{\circ} \mathrm{C}$ and stored until further processing. Dumpsite plastic samples were collected from five sites and stored at $4{ }^{\circ} \mathrm{C}$. They were mixed to use as an inoculum for setting the enrichment within $48 \mathrm{~h}$ of sample collection. Drilling fluid $(1 \mathrm{~g}$ each) samples were incubated with $10 \mathrm{~mL}$ sodium pyrophosphate $(0.1 \% \mathrm{w} / \mathrm{v})$ overnight under shaking condition to dislodge the cells, and one $\mathrm{mL}$ of the supernatant was used as final inoculum.

The carbon free basal medium used for the enrichment of LDPE degrading bacteria had the following composition: $12.5 \mathrm{~g} / \mathrm{L} \mathrm{K} \mathrm{HPO}_{4} ; 3.8 \mathrm{~g} / \mathrm{L} \mathrm{KH}_{2} \mathrm{PO}_{4} ; 1.0 \mathrm{~g} / \mathrm{L}\left(\mathrm{NH}_{4}\right)_{2} \mathrm{SO}_{4} ; 0.1 \mathrm{~g} / \mathrm{L}$ $\mathrm{MgSO}_{4} \cdot 7 \mathrm{H}_{2} \mathrm{O}(\mathrm{pH} 7.0)$ and $5 \mathrm{~mL}$ trace element solution was mixed in $1 \mathrm{~L}$ of the medium. The trace element solution consisted of the following: $0.232 \mathrm{~g} / \mathrm{L} \mathrm{H}_{3} \mathrm{BO}_{3} ; 0.174 \mathrm{~g} / \mathrm{L} \mathrm{ZnSO}_{4} \cdot 7 \mathrm{H}_{2} \mathrm{O}$; $0.116 \mathrm{~g} / \mathrm{L} \mathrm{FeSO}_{4}\left(\mathrm{NH}_{4}\right)_{2} \mathrm{SO}_{4} \cdot 6 \mathrm{H}_{2} \mathrm{O} ; 0.096 \mathrm{~g} / \mathrm{L} \mathrm{CoSO}_{4} \cdot 7 \mathrm{H}_{2} \mathrm{O}$; $0.022 \mathrm{~g} / \mathrm{L}\left(\mathrm{NH}_{4}\right)_{6} \mathrm{Mo}_{7} \mathrm{O}_{24} \cdot 4 \mathrm{H}_{2} \mathrm{O} ; 8.0 \mathrm{~g} / \mathrm{L} \mathrm{CuSO}_{4} \cdot 5 \mathrm{H}_{2} \mathrm{O} ; 8.0 \mathrm{~g} / \mathrm{L}$ $\mathrm{MnSO}_{4} \cdot 4 \mathrm{H}_{2} \mathrm{O}$ (Kyaw et al., 2012). Reasoner's $2 \mathrm{~A}$ agar (modified to reduce the carbon content by 10 fold) was used for isolation of bacterial strains containing the following components: $0.05 \mathrm{~g} / \mathrm{L}$ Yeast extract, $0.05 \mathrm{~g} / \mathrm{L}$ Peptone, $0.5 \mathrm{~g} / \mathrm{L}$ Casamino acid, $0.05 \mathrm{~g} / \mathrm{L}$ Glucose, $0.05 \mathrm{~g} / \mathrm{L}$ Starch, $0.3 \mathrm{~g} / \mathrm{L} \mathrm{K}_{2} \mathrm{HPO}_{4}, 0.05 \mathrm{~g} / \mathrm{L} \mathrm{MgSO}$, $0.3 \mathrm{~g} / \mathrm{L}$ Sodium Pyruvate; $15 \mathrm{~g} / \mathrm{L}$ Agar. The composition of modified Luria Bertani (LB) agar medium (M/5) used to determine the biofilm cell growth was as follows: Casein enzyme hydrolyzate $2 \mathrm{~g} / \mathrm{L}$, Yeast extract $1 \mathrm{~g} / \mathrm{L}$, Sodium chloride $2 \mathrm{~g} / \mathrm{L}$, Agar $15 \mathrm{~g} / \mathrm{L}(\mathrm{pH}=7.5 \pm 0.2)$. All the enrichment setups were incubated aerobically at $30{ }^{\circ} \mathrm{C}$ in an incubator shaker at $150 \mathrm{rpm}$ for 100 days.

\section{Enrichment (Setup) and Isolation of PE Degrading Bacteria}

P (approximately 10 pieces) and DF (DF2, DF4, DF7) (1 mL) samples were inoculated in $100 \mathrm{~mL}$ of basal medium with LDPE as C source. Ten sterilized LDPE beads of around $0.3 \mathrm{~g}$ were used as the sole carbon source. Along with that, separate negative control (without inoculum) was prepared. The samples along with negative control (without bacterial inoculum) were kept at $30^{\circ} \mathrm{C}$ for 100 days in an incubator shaker $(150 \mathrm{rpm})$. All experiments were set up in duplicates.

After incubation, biofilm or the bacteria present on the surface of the plastic beads were collected according to Kyaw et al. (2012). The beads were immersed in $2 \mathrm{~mL}$ of $0.9 \%$ $\mathrm{NaCl}$. They were incubated overnight at room temperature. After incubation, they were vortexed properly for few minutes in order to prepare a cell suspension. Hundred $\mu \mathrm{L}$ liquid cell suspension from each sample was inoculated on the modified R2A agar and kept for incubation at $30{ }^{\circ} \mathrm{C}$ for $48 \mathrm{~h}$. The colonies obtained were sub-cultured on the same medium for further studies.

\section{Measurement of Microbial Cell Growth and Change in Medium pH}

Following microbial growth, biofilm formation on the surface of the LDPE beads was determined according to the method described by Manijeh et al. (2008). LDPE beads from enrichment cultures were suspended into $0.9 \% \mathrm{NaCl}$ and vortexed after overnight incubation as described earlier. The resulting suspension was serially diluted within $0.9 \% \mathrm{NaCl}$ up to $10^{5}$ fold and $0.1 \mathrm{~mL}$ of the diluted sample was plated on modified Luria Bertani Agar plates. The CFU was counted after overnight incubation at $30{ }^{\circ} \mathrm{C}$ and the following formula was used to determine the biofilm cell growth.

Biofilm cell growth $=\log [$ (average $\mathrm{CFU} / \mathrm{drop}$ volume $) \times$ (dilution counted) $\times$ (volume scraped into/ surface area)].

In order to measure the microbial growth after incubation, $1 \mathrm{~mL}$ of liquid suspension was taken and absorbance $\left(\mathrm{OD}_{600}\right)$ was determined using a UV-VIS spectrophotometer. Similarly, change in $\mathrm{pH}$ was also monitored using a $\mathrm{pH}$ meter. 


\section{PE Weight Reduction and Hydrophobicity}

LDPE beads recovered from the enrichment cultures after 100 days of incubation were washed properly to remove the microbial cells to get the accurate measurement of the weight. These beads were incubated with $2 \%(\mathrm{w} / \mathrm{v})$ aqueous sodium dodecyl sulfate solution for $4 \mathrm{~h}$ in shaking condition, followed by washing with distilled water and $70 \%$ ethanol in order to remove the bacterial cells and other cell debris (Orr et al., 2004). The beads were dried at $70{ }^{\circ} \mathrm{C}$. The weight reduction percentage was calculated using the formula mentioned below (Kyaw et al., 2012).

Percentage of Weight Reduction $=($ Initial Weight - Final Weight $) \times 100 /$ Initial Weight

Bacterial adhesion to hydrocarbon (BATH) test was carried out to calculate the bacterial cell surface hydrophobicity (Rosenberg et al., 1980). Microorganisms enriched in the different setups were re-inoculated in R2A agar medium and were allowed to grow until they reached mid-logarithmic phase. The microbial cell pellets were obtained by centrifugation and washed with PBS buffer ( $\mathrm{pH}$ 7.1). The washed cell pellets were re-suspended in fresh PBS buffer. Aliquots of $4 \mathrm{~mL}$ each were transferred from the resuspension to fresh test tubes and $1.5 \mathrm{~mL}$ of hexadecane was added to them. Solution was vortexed for $2 \mathrm{~min}$ and kept still for $15 \mathrm{~min}$ to obtain the phase separation. The optical density of the separated phase was measured at $600 \mathrm{~nm}$ $\left(\mathrm{OD}_{600}\right)$. Cell-free buffer served as blank. Adherence percentage to hexadecane or BATH was determined using the following formula (Tribedi and Sil, 2013).

Cell surface hydrophobicity $(\%)=100 \times\{($ initial OD - final OD)/initial OD\}

\section{Isolation and Identification of LDPE Degrading Bacterial Strains}

Following 100 days of incubation, microbial cells present on the LDPE surface of the enrichments, which displayed better plastic degradation, were dislodged in $0.9 \% \mathrm{NaCl}$. Hundred $\mu \mathrm{L}$ of cell suspension was plated on modified R2A agar supplemented medium and incubated for $48 \mathrm{~h}$ to obtain morphologically distinct colonies. The obtained isolates were routinely sub-cultured on same medium at $30{ }^{\circ} \mathrm{C}$ and preserved with glycerol $(25 \%, \mathrm{v} / \mathrm{v})$ at $-80{ }^{\circ} \mathrm{C}$. The genomic DNA of isolates (P2, DF22) was extracted using DNA minikit protocol following SDS-Lysozyme lysis and subsequent purification using phenol:chloroform:isoamyl alcohol and ethanol (Mohapatra et al., 2018). The 16S rRNA gene was amplified by PCR with bacterial universal primers (27F: 5'-AGAGTTTGATCCTGGCTCAG-3' and 1492R: 5'TACCTTGTTACGACTT- $3^{\prime}$ ). The PCR cycle composed of an initial denaturation step at $95{ }^{\circ} \mathrm{C}$ for $5 \mathrm{~min}, 35$ cycles of $95^{\circ} \mathrm{C}$ for $45 \mathrm{~s}, 58{ }^{\circ} \mathrm{C}$ for $45 \mathrm{~s}, 72{ }^{\circ} \mathrm{C}$ for $1.5 \mathrm{~min}$, and with a final extension of $72{ }^{\circ} \mathrm{C}$ for $7 \mathrm{~min}$. The PCR products were gel purified using a Qia-quick gel extraction kit (QIAGEN), cloned into pTZ57R/T vector (InsTA clone kit, Thermo Fisher Scientific, Waltham, MA, United States), and sequenced using $27 \mathrm{~F}$ and $1492 \mathrm{R}$, followed by extraction of true nucleotide positions using BioEdit version 7.2.5. Assembly of the whole stretch was done using CAP contig assembly program of BioEdit to obtain $\sim 1000$ bp sequence of 16S rRNA gene. Homology search for maximum similarity of the $16 \mathrm{~S}$ rRNA gene sequences was carried out using identity tool of EzTaxon-e server ${ }^{1}$ and BlastN of NCBI database considering validly published and effectively described type species. Whereas 16S rRNA gene sequences of other non-type species were obtained from NCBI database. Multiple alignments were performed with CLUSTALW package of MEGA X (Kumar et al., 2018), where all ambiguous positions were removed in the final dataset using pairwise deletion option. Phylogenetic reconstruction and validation were performed using neighbor-joining (NJ) algorithm (Saitou and Nei, 1987) with 1000 bootstrap re-iterations using Jukes-Cantor distance model (Jukes and Cantor, 1969). Both maximumlikelihood (ML; Felsenstein, 1981) and minimum-evolution (ME; Takahashi and Nei, 2000) methods were employed to test the robustness of the trees. The sequences were submitted to NCBI GenBank under the accession numbers: MT929273 (DF22) and MT929274 (P2).

\section{PE Biodegradation by Isolated Bacterial Strains}

The isolated bacterial strains were checked for their plastic degradation potential. The freshly grown cells (1\%) were added to $100 \mathrm{~mL}$ of basal medium, where 10 pieces of sterile plastic films of around $2 \mathrm{~cm}^{2}$ each (total $0.24 \mathrm{~g}$ ) were used in each sample as sole carbon source. They were incubated aerobically at $30{ }^{\circ} \mathrm{C}$ in shaking condition at $150 \mathrm{rpm}$. After 45 days, the set ups were examined to check the biodegradation of the plastic films. A control which had no inoculum was incubated along with the samples.

\section{Morphological Analysis of PE films by Atomic Force Microscopy (AFM)}

Changes on the surface of PE films due to the treatment of bacteria were visualized under Atomic Force Microscope (AFM) (Agilent Technologies Inc., United States). The polythene films were taken out from the basal medium and they were thoroughly washed with $2 \%$ sodium dodecyl sulfate to clean the surface. Thereafter, the films were dried overnight at $50^{\circ} \mathrm{C}$ and the dried PE films were used for examination under AFM (Gajendiran et al., 2016). The LDPE samples were analyzed with a scan speed of $1.0 \mathrm{~Hz}$ and a resolution of $256 \times 256$ pixels.

\section{Surface Morphology Analysis of PE Films by Scanning Electron Microscopy (SEM)}

$\mathrm{PE}$ films were also visualized under Scanning Electron Microscope (SEM), in order to examine the surface morphology changes due to microbial action. The PE films were treated with $2 \%$ SDS and dried at $50{ }^{\circ} \mathrm{C}$ as described above in order to remove the microbial cells and associated derbies. Finally, they were gold coated, and viewed under SEM (SEM, ZEISS and Focused Ion Beam SEM, Germany) using a $\mathrm{Cu}$ grid at 2500X magnification (Das and Kumar, 2015).

\footnotetext{
${ }^{1}$ https://www.ezbiocloud.net/identify
} 


\section{Fourier Transform Infrared Spectroscopy (FTIR) of PE Films}

The modification of polyethylene in terms of chemical bonds due to the action of the isolated bacterial strains was assessed by Fourier Transform Infrared Spectroscopy (Thermo Scientific IR Spectrophotometer, United States). Microbially treated and untreated polyethylene films were taken out after 45 days and washed with $2 \%$ SDS and dried at $50{ }^{\circ} \mathrm{C}$ as described earlier. Finally, control and treated PEs were analyzed under the IR spectrophotometer using transmission mode (Kowalczyk et al., 2016).

\section{RESULTS}

\section{Enrichment of PE Degrading Bacterial Cells and Indication of Degradation}

Enrichment of PE degrading bacterial cells was attempted by incubating LDPE beads with four different samples (namely, P, DF2, DF4, and DF7). Following 100 days incubation, various parameters related to cell growth and change in culture $\mathrm{pH}$ were measured. Cell growth was measured in terms of culture OD followed by measurement of primary indication of plastic biodegradation by monitoring weight reduction of the LDPE beads, cell surface hydrophobicity and biofilm cell growth (Figure 1).

The $\mathrm{OD}_{600}$ of the medium showed significant change in turbidity, thus indicating possible cell growth following 100 days' incubation. Highest absorbance was shown by DF7, followed by $P>$ DF4 and DF2 displayed the least (Figure 1A). Control set showed very low OD. Biofilm growth measured by recovering the LDPE beads from the incubation flasks showed considerable cell growth (Figure 1B). Compared to control beads with negligible $\mathrm{CFU}$ counts, beads from $\mathrm{P}$ setup yielded highest CFU of $10^{6} / \mathrm{cm}^{2}$, followed by the beads from DF4 culture $\left(6 \times 10^{5} / \mathrm{cm}^{2}\right)>$ DF2 $\left(3 \times 10^{5} / \mathrm{cm}^{2}\right)$ and DF7 $\left(9 \times 10^{4} / \mathrm{cm}^{2}\right)$. It was noticed that the sample treated with landfill plastic associated soil $(\mathrm{P})$ showed higher biofilm cell growth compared to the samples inoculated with drilling fluids (DF).

Compared to nearly unaltered $\mathrm{pH}$ of the control set, a drastic change in solution $\mathrm{pH}$ tending toward acidic $\mathrm{pH}$ from neutral $\mathrm{pH}$ was noted for all the biotic samples (Figure 1C). Among these, $\mathrm{P}$ showed a maximum decrease in $\mathrm{pH}$ (from $\mathrm{pH} 7.0$ to $\mathrm{pH}$ 5.6) followed by DF2 ( $\mathrm{pH} 6.0$ from $\mathrm{pH}$ 7.0). Significant weight loss of the LDPE beads was observed in this study following their incubation (Figure 1E). Drilling fluid sample DF2 showed maximum reduction (7.54\%) followed by P (7.45\%), much higher than the untreated sample (no change in weight). This was a preliminary estimation of degradation since the bacteria present in the samples would utilize polyethylene, which was the only carbon source, thus leading to weight reduction of the plastic (Kyaw et al., 2012). The cell surface hydrophobicity was determined by BATH assay, which revealed that all the treated samples had more than $80 \%$ hydrophobicity except drilling fluid sample DF2 (having 66.42\%) but the untreated sample (C) had only $11.11 \%$ hydrophobicity (Figure 1D). This assay showed the affinity of the bacterial cells toward the organic hydrocarbon thus highlighting the capability of enriched microbes in adhering to the polyethylene surface. This might result in enhancing the biofilm formation and degradation process (Sarker et al., 2020).

Depending on the abovementioned parameters, it was conferred that the samples P and DF2 showed better response toward biodegradation and they were selected for further analyses as well as isolation of bacterial strains. Two morphologically distinct LDPE degrading bacterial isolates were obtained as pure culture from P and DF2 enrichments. These two isolates (designated as P2 and DF22) were identified and further characterized for their LDPE degrading ability.

\section{$16 S$ rRNA Gene Phylogenetic Analysis of PE Degrading Isolates}

EzTaxon and BLAST based comparative homology analysis of 16S rRNA gene sequences ( $1000 \mathrm{bp})$ of PE degrading isolates, P2 and DF22 showed belongingness to members of Stenotrophomonas and Achromobacter, respectively. Isolate P2 displayed maximum identities of $99.4 \%$ to type strain of Stenotrophomonas pavanii DSM $25135^{T}$, followed by other Stenotrophomonas type species (95.48-98.56\%). Whereas isolate DF22 showed maximum of $97.6 \%$ identity to type strain of Achromobacter xylosoxidans NBRC $15126^{T}$, followed by $<97.0 \%$ similarity with all other type members. Neighborjoining phylogenetic reconstruction showed that P2 formed coherent cluster with the type strain S. pavanii DSM $25135^{\mathrm{T}}$, while DF22 showed its maximum evolutionary closeness with several members (A. xylosoxidans NBRC 15126, EC3, A. insolitus DSM 23807, etc.) (Figure 2). Bootstrap re-sampling analysis together with combined ML and ME based phylogeny displayed similar tree topology demonstrating a strong association of Stenotrophomonas P2 with its closest relative S. pavanii DSM $25135^{T}$. Whereas, Achromobacter sp. DF22 was denoted to be phylogenetically distinct among Achromobacter spp.

Phylogenetic analysis involving various plastics (LDPE, HDPE)/polymer degrading type- and non-type members of Stenotrophomonas and Achromobacter from different habitats showed that isolate P2 was taxonomically closest to the $S$. pavanii PDS-5, which has been characterized to be a polyethylene degrading bacterium from contaminated habitat. Thus, it denoted species level affiliation of $\mathrm{P} 2$ to the $S$. pavanii members (Figure 2). Isolate DF22 showed distant relatedness with plastic/polymer degrading Achromobacter species members (Figure 2). Isolates P2 and DF22 were designated as Stenotrophomonas sp. P2 and Achromobacter sp. DF22.

\section{Atomic Force Microscopy and Scanning Electron Microscopy}

Changes in surface morphology of the LDPE films were examined by Atomic Force Microscopy (AFM). The topography images of the treated films showed formation of grooves, corrosions, cracks and pits, etc., (Figures 3B,C). These changes were not observed in the untreated samples (Figure 3A). Modification 

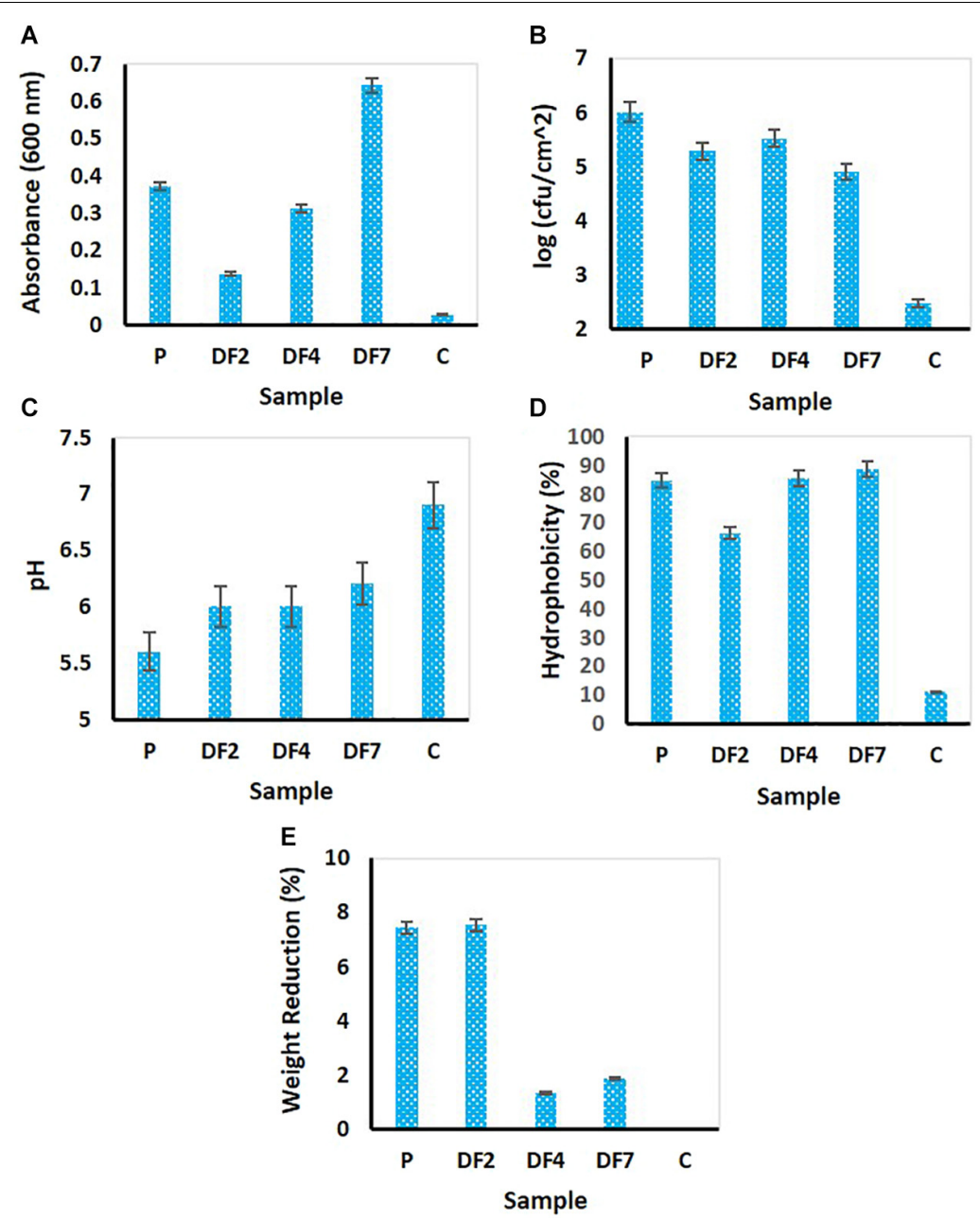

FIGURE 1 | Estimation of cellular activities of microorganisms enriched with LDPE following 100 days' incubation. (A) culture turbidity as measured through OD 600 ; (B) measurement of biofilm cell growth; (C) change in medium $\mathrm{pH}$; (D) measurement of cell surface hydrophobicity and (E) measurement of weight reduction of the LDPE beads.P: Enrichment derived from waste dumpsite; DF2, DF4, and DF7: Enrichments using drilling fluid as the source of microbes. The analyses were performed in multiple ( $n=3-5$ replicates). The mean data were used for preparation of the figure.

in the surface morphology might be facilitated due to the action of microorganisms in the treated samples. AFM also indicated toward changes in the roughness of the surface, thus giving an overall idea on surface modification of the treated samples. The incubation for 45 days with the isolated strains caused significant increase in nano-roughness parameters, namely $\mathrm{Ra}$ (mean deviation of roughness), Rq (root mean square deviation of roughness), $\mathrm{Rz}$ (maximum height of roughness), $\mathrm{Rv}$ (maximum valley depth of roughness), Rp (maximum peak height of roughness) (Figure 3D), when compared to the untreated plastic. This indicated toward the formation of grooves as the result of enzymatic degradation of the LDPE (Peixoto et al., 2017). Stenotrophomonas sp. P2 displayed more maximum height $(154 \mathrm{~nm})$ than Achromobacter sp. DF22 (132 nm) and untreated films had the lowest $(80 \mathrm{~nm})$ for the same. Maximum height was the mathematical visualization of the topographs. It was noticed that Stenotrophomonas sp. P2 displayed more differences in maximum height, $\mathrm{Rv}, \mathrm{Rq}, \mathrm{Ra}$ and Achromobacter sp. DF22 had more changes in Rz, Rp (Figures 3A-D). Post incubation, roughness parameters were increased as much as two to three fold due to the action of both the strains.

Scanning Electron Microscopy (SEM) was performed next to further validate the LDPE surface modification due to the enzymatic action of microbes. Significant alterations on the surface of treated (with microorganisms) films were clearly observed, indicating toward the primary release of debris due to microbial action. Presence of cracks, erosions and grooves was significantly noted in the treated samples (Figures 4B,C); whereas the surface of the control or the untreated LDPE was mostly smooth (Figure 4A).

\section{Assay of Biodegradation by Spectroscopy}

The FTIR spectroscopic analysis of the LDPE films after 45 days of incubation gave several insights into the process of chemical bond modification. When compared with the untreated plastic 


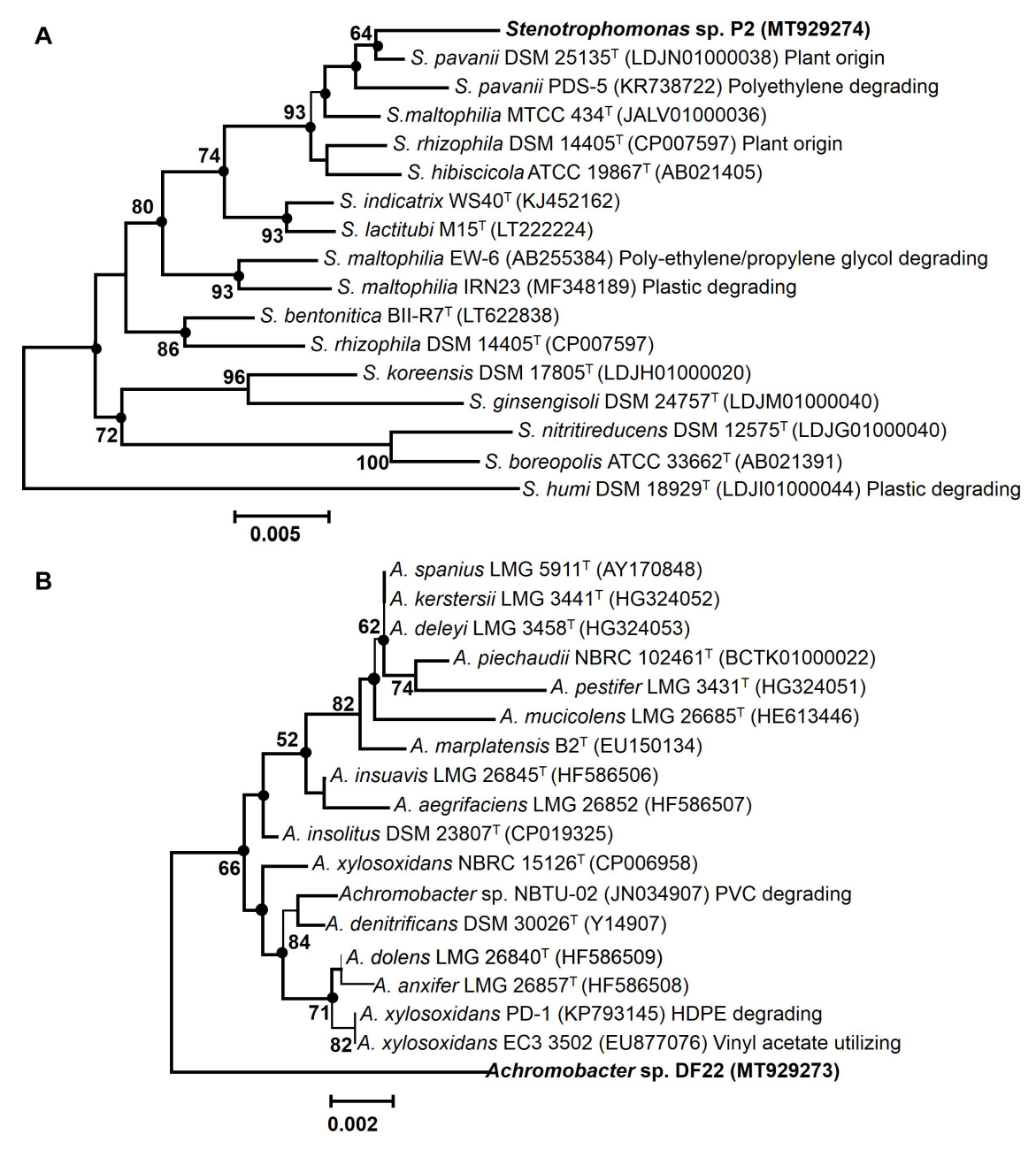

FIGURE 2 | Maximum Composite Likelihood based neighbor-joining (NJ) phylogenetic reconstruction of 16S rRNA gene sequences of LDPE degrading isolates [P2 (A), DF22 (B), in bold] with validly described type species (T) and non-type members with various plastic degrading abilities of respective taxa. The percentage of replicate trees (>50\%) based on bootstrap iterations (1000 replicates) are shown next to the branches. The filled circles indicate the corresponding branches and nodes obtained from both Maximum-Likelihood (ML) and Minimum Evolution (ME) trees. Bars, 0.005 and 0.002 represent $0.5 \%$ and $0.2 \%$ nucleotide substitutions.

film, changes in FTIR spectra in few unique wavelengths in the treated LDPE films were found which confirmed the modification of bonds and generation of new bonds or functional groups in the polyethylene backbone due to the biotic treatment. Majorly altered and the significant characteristic bands were found between $600 \mathrm{~cm}^{-1}$ and $2000 \mathrm{~cm}^{-1}$. Treated and untreated samples had few common peaks that belonged to polyethylene. Peaks at $720 \mathrm{~cm}^{-1}$ and near $1450 \mathrm{~cm}^{-1}$ were formed due to the long chain of C-H (bending vibration) (Yang et al., 2014). The peaks that were different from the control represented the main changes in chemical bonds and incorporation of functional groups. The formation of alkoxy groups, C-O (1000 $\mathrm{cm}^{-1}$ to $\left.1090 \mathrm{~cm}^{-1}\right)$; nitro groups, $\mathrm{N}-\mathrm{O}\left(1500 \mathrm{~cm}^{-1}\right.$ to $1600 \mathrm{~cm}^{-1}$ ); acyl groups, C-O (peak at $1220 \mathrm{~cm}^{-1}$ ) and carbonyl groups, $\mathrm{C}=\mathrm{O}$ (peak near $1720 \mathrm{~cm}^{-1}$ ) was mainly found. In addition, some other modifications were observed, i.e., chain scission, $\mathrm{H}_{2} \mathrm{C}=\mathrm{C}$ - $\left(905 \mathrm{~cm}^{-1}\right)$ and $\mathrm{N}-\mathrm{O}$ stretching (peak at $1360 \mathrm{~cm}^{-1}$ ) (Figure 5A). The bacterial enzymes could easily utilize these groups as their function site. Also, the double bond of carbon would be more accessible by bacteria compared to C-C. Chemical bond formation and modification obtained through FTIR spectroscopy helped us to understand the mechanism of enzymatic degradation of LDPE. Apart from the graph, some indices like Carbonyl Index (CI), Double Bond Index (DBI) and Terminal Double Bond Index (TDBI) were calculated to evaluate functional bond formation and LDPE chain modifications such as oxidation, vinylene formation and chain scissioning (Figures 5B,C). Treated LDPE showed significant increase in CI as much as 15-20 fold (Figure 5B) along with 1.52 times increase in DBI and 30-40 fold rise in TBDI (Figure 5C). The significant increase of the indices in case of the treated samples was quite promising as a result of biodegradation. The bacteria used LDPE as their source of carbon and made the necessary changes incorporating the functional groups to modify them into simpler products like alcohol, ketone, fatty acids, etc., (Peixoto et al., 2017). 

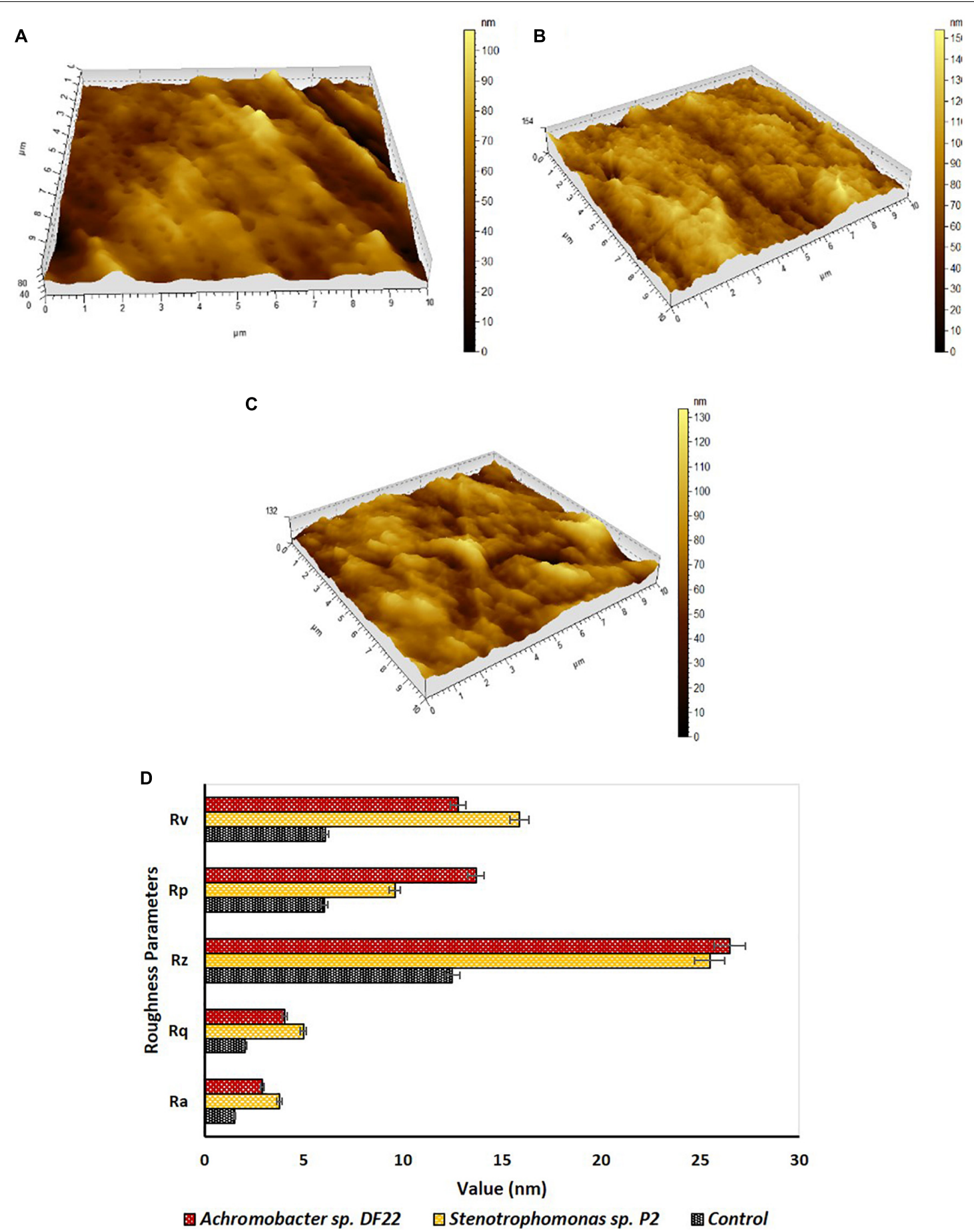

FIGURE 3 | Investigation of surface topography and roughness parameters by AFM. Topography of plastic samples (A) control (untreated) and treated with (B) Stenotrophomonas sp. P2 and (C) Achromobacter sp DF22 after 45 days of incubation. (D) In comparison to Control (Black), increase in roughness parameters [average roughness $(\mathrm{Ra})$, root mean square roughness $(\mathrm{Rq})$, average height $(\mathrm{Rz})$, maximum peak height (Rp), and maximum valley depth (Rv)] was observed for the LDPE films treated with Stenotrophomonas sp. P2 (orange) and Achromobacter sp. DF22 (brown).

\section{DISCUSSION}

Samples from municipal waste dumpsite soil and bentonite based drilling fluid from a deep subsurface drilling operation were collected and used to enrich indigenous microorganisms capable of LDPE biodegradation. Microbial populations inhabiting the landfills have been already explored by several researchers for their polyethylene degrading potential (Gajendiran et al., 2016; 

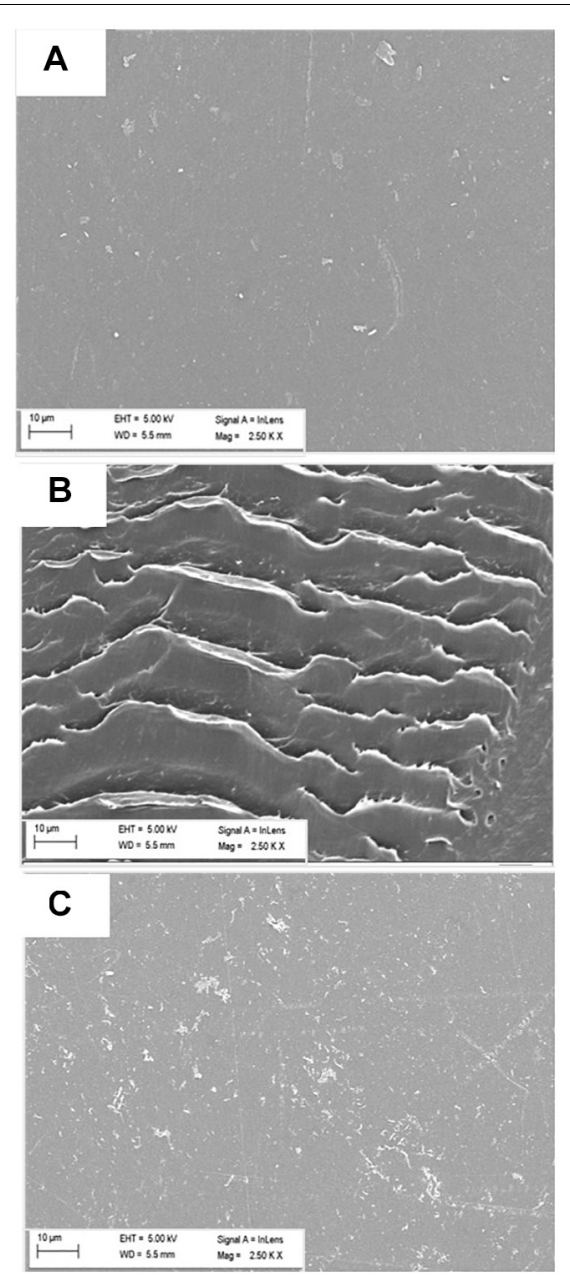

FIGURE 4 | Modification of surface morphology of LDPE films (A) untreated, and treated with (B) Stenotrophomonas sp. P2 and (C) Achromobacter sp. DF22 observed under SEM at $2500 \times$ amplification. Changes on the surface in terms of corrosion, crack formation, etc., were visible only for the treated samples after the incubation period.

Kowalczyk et al., 2016; Muhonja et al., 2018; Park and Kim, 2019). Regarding the microorganisms of drilling fluids used in deep subsurface drilling operations, various studies have reported their taxonomic versatility and biodegradation potential (Alekhina et al., 2007; Ozyurek and Bilkay, 2017, 2018; Bose et al., 2020). Plastic metabolizing ability of such bacteria, however, has not been explored in detail.

All the test samples were incubated aerobically in a carbon free basal medium with LDPE beads as sole carbon source for 100 days. Visible growth and turbidity in the medium post incubation confirmed the successful enrichment of LDPE degrading microorganisms. Decrease of medium $\mathrm{pH}$ to an acidic range suggested the metabolic activity of the enriched cells (Duddu et al., 2015). The fragmentation and depolymerization of LDPE would lead to the formation of smaller molecular weight products such as fatty acids, organic acids, etc., which might cause the decrease in $\mathrm{pH}$
(Das and Kumar, 2015; Karamanlioglu et al., 2017). Decrease in medium $\mathrm{pH}$ and increase in absorbance of the medium for all the samples established that the enriched microorganisms could utilize LDPE as sole carbon source. This increase in absorbance could also reflect the possibility of the presence of fragmented LDPEs as a result of microbial action (Chatterjee et al., 2010). These enrichment cultures and the LDPE beads were subjected to series of tests for further evaluation of their LDPE degradation potential. High biofilm cell growth and effective colonization on the surface of the treated LDPE beads in all the test samples indicated toward the enrichment of LDPE degrading microorganisms. Biofilm formation on the surface of the hydrophobic and high molecular weight plastic polymers, such as LDPE is considered as one of the most important steps of microbial degradation of these polymers (Sivan, 2011). Furthermore, it has been already reported that the cells in biofilms are known to secrete exopolysaccharides that aid in their attachment to the surface of hydrophobic plastic polymers (Wilkes and Aristilde, 2017 and reference therein). Biofilm formation enabled the microorganisms to attach and efficiently utilize the non-soluble substrate via various enzymatic reactions (Orr et al., 2004; Peixoto et al., 2017). High cell surface hydrophobicity in all the test samples further confirmed the biofilm formation, as the hydrophobicity of any organism has a direct correlation with its potential to bind to non-polar hydrocarbons such as polyethylene (Sanin et al., 2003; Tribedi and Sil, 2013; Sarker et al., 2020). Highest weight loss of treated LDPE beads recovered from P and DF2 samples indicated that microbial consortia enriched from these two samples were more efficient in LDPE degradation. This weight reduction must have taken place because of the enzymatic action of the enriched microorganisms attached to the LDPE surface (Kyaw et al., 2012; Gajendiran et al., 2016). These two microbial consortia also displayed quite high metabolic activity. Overall, microbial consortia enriched from both landfill and drilling fluid samples showed promising capability of LDPE degradation. Microbial consortia enriched from P and DF2 samples were found to be more efficient toward LDPE degradation. They were further used for isolation of LDPE degrading bacteria.

Two LDPE degrading bacterial isolates, P2 and DF22 were obtained as pure culture from these enrichments. The isolated strains P2 and DF22 showed closest affiliation with microorganisms belonging to Stenotrophomonas and Achromobacter respectively. Phylogenetic analysis of the isolates denoted species level affiliation of Stenotrophomonas sp. P2 to the $S$. pavanii members. Based on the published criteria of $<98.65 \%$ (cut-off) of $16 \mathrm{~S}$ rDNA similarity for differentiating two species members and description of new species (Kim et al., 2014), Achromobacter sp. DF22 might represent a new (novel) species within the genus Achromobacter. S. pavani PDS-5 (taxonomically closest to Stenotrophomonas sp. P2) has been already identified as a potent polyethylene degrader (Mehmood et al., 2016). Earlier studies have also reported the ability of other microbial members (Table 1) belonging to this genus toward plastic degradation (Abe et al., 2010; Peixoto et al., 2017; Montazer et al., 2018). Besides, Stenotrophomonas spp. have also been used for the bioremediation of organic pollutants 


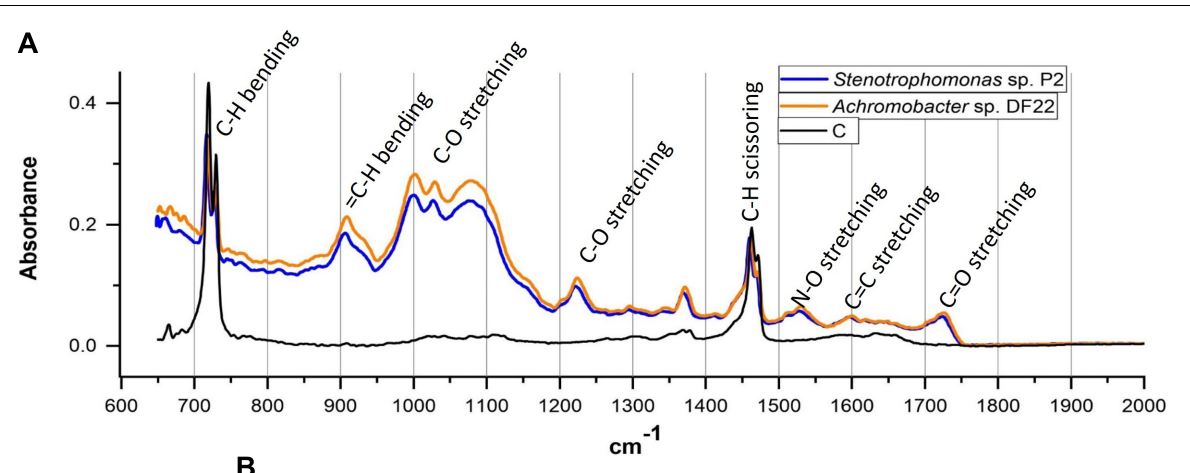

B

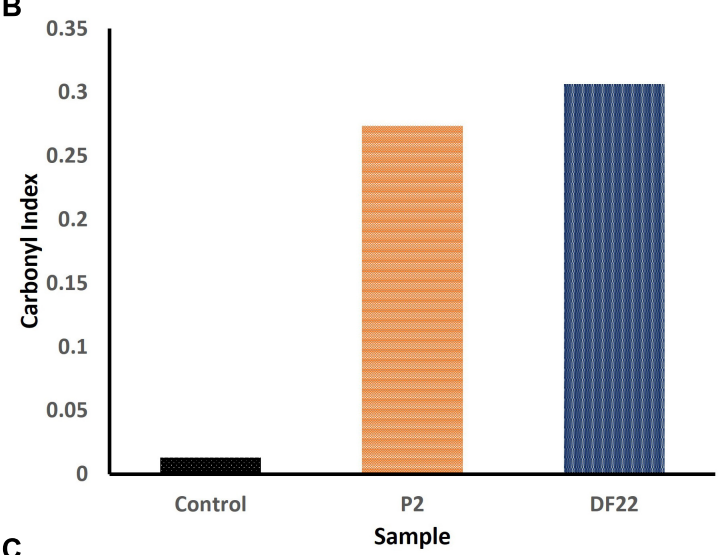

C

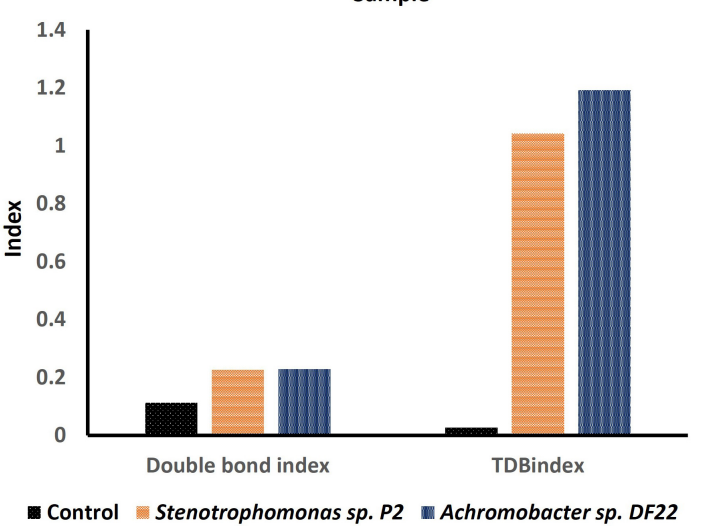

FIGURE 5 | (A) FTIR spectra of plastic films after treating with Stenotrophomonas sp. P2 (Blue) and Achromobacter sp. DF22 (Orange) showing the clear differences in the chemical bonds compared to control (Black) due to the bacterial treatment. (B) Change in Carbonyl Index (Cl) for LDPE treated with Stenotrophomonas sp. P2 (P2: Orange) and Achromobacter sp. DF22 (DF22: Deep blue). (C) Changes in Double Bond Index and Terminal Double Bond Index (TDBindex) for the LDPE films incubated with Stenotrophomonas sp. P2 (Orange) and Achromobacter sp. DF22 (Deep blue) compared to Control (Black).

like fenvalerate, 3-phenoxybenzoic acid, dibenzothiophene, etc., (Chen et al., 2011; Papizadeh et al., 2011). These members were found to be distantly related to Stenotrophomonas sp. P2. Such phylogenetic clustering could be the result of similar evolutionary changes and shared metabolic tendency as isolate P2 showed its ability to degrade/impact the LDPE in the medium and isolated as LDPE enriched culture. Microbial members belonging to the genus Achromobacter have also displayed their ability toward degradation of plastic based polymers. Kowalczyk et al., 2016 has successfully tested HDPE biodegradation ability of Achromobacter xylosoxidans, which was isolated from landfill soil. Achromobacter sp. NBTU-02 has shown its potential toward biodegradation of plastics (Das et al., 2012). Along with these strains, some other strains having polyethylene degrading capabilities had been isolated from various environments and their potential toward PE biodegradation was examined by determining weight reduction, cell surface hydrophobicity, chemical modification, surface morphology changes, etc., (Table 1). Stenotrophomonas sp. P2 and Achromobacter sp. DF22 were further tested for their ability toward LDPE degradation.

Both the strains were incubated aerobically for 45 days in a carbon free basal medium, using LDPE films as sole $\mathrm{C}$ source. Following incubation, the films were examined for 
TABLE 1 | Bacterial members used for biodegradation of various polyethylene (PE) materials from diverse contaminated habitats.

\begin{tabular}{|c|c|c|c|c|c|}
\hline Organisms & Isolation source & Plastic polymer & $\begin{array}{l}\text { Incubation duration } \\
\text { (days) }\end{array}$ & $\begin{array}{l}\text { Biodegradation } \\
\text { observations }\end{array}$ & References \\
\hline $\begin{array}{l}\text { Stenotrophomonas sp. } \\
\text { P2 }\end{array}$ & Waste dump site & LDPE & 100 & $\begin{array}{l}\sim 8 \% \text { weight reduction, biofilm, } \\
\text { structural deformity, surface } \\
\text { hydrophobicity, Chemical } \\
\text { stability change }\end{array}$ & This Study \\
\hline $\begin{array}{l}\text { Achromobacter sp. } \\
\text { DF22 }\end{array}$ & Waste dump site & LDPE & 100 & $\begin{array}{l}\sim 8 \% \text { weight reduction, biofilm, } \\
\text { surface hydrophobicity, } \\
\text { structural deformity, Chemical } \\
\text { stability change }\end{array}$ & This Study \\
\hline $\begin{array}{l}\text { Stenotrophomonas } \\
\text { pavanii }\end{array}$ & Solid waste dump site & Modified LDPE & 56 & Chemical alteration & Mehmood et al., 2016 \\
\hline Stenotrophomonas sp. & Soil with plastic debris & LDPE & 90 & Chemical stability change & Peixoto et al., 2017 \\
\hline $\begin{array}{l}\text { Achromobacter } \\
\text { xylosoxidans }\end{array}$ & Landfill soil & HDPE & 150 & $\begin{array}{l}9 \% \text { weight reduction and } \\
\text { chemical alteration }\end{array}$ & Kowalczyk et al., 2016 \\
\hline $\begin{array}{l}\text { Acinetobacter } \\
\text { baumannii }\end{array}$ & Municipal landfill & $\mathrm{PE}$ & 30 & Biomass increase & $\begin{array}{l}\text { Pramila and Ramesh, } \\
2015\end{array}$ \\
\hline Comamonas sp. & Soil with plastic debris & LDPE & 90 & Chemical stability change & Peixoto et al., 2017 \\
\hline Delftia sp. & Soil with plastic debris & LDPE & 90 & Chemical stability change & Peixoto et al., 2017 \\
\hline Kocuria palustris M16 & Pelagic waters & PE bags & 30 & $1 \%$ weight reduction & $\begin{array}{l}\text { Harshvardhan and Jha, } \\
2013\end{array}$ \\
\hline $\begin{array}{l}\text { Microbacterium } \\
\text { paraoxydans }\end{array}$ & Clinical sample & Pretreated LDPE & 60 & $61 \%$ weight reduction & Rajandas et al., 2012 \\
\hline Pseudomonas sp. & Mangrove soil & $\mathrm{PE}$ & 30 & $20.5 \%$ weight reduction & Kathiresan, 2003 \\
\hline $\begin{array}{l}\text { Pseudomonas } \\
\text { aeruginosa }\end{array}$ & Petroleum soil & Low mol. Wt. PE & 80 & $41 \%$ weight reduction & Jeon and Kim, 2015 \\
\hline Pseudomonas sp. & Garbage soil & PE bags & 180 & $37 \%$ weight reduction & Usha et al., 2011 \\
\hline $\begin{array}{l}\text { Pseudomonas } \\
\text { citronellolis }\end{array}$ & Municipal landfill & LDPE & 4 & $17.8 \%$ weight reduction & Bhatia et al., 2014 \\
\hline Pseudomonas putida & Soil with plastic debris & $\mathrm{PE}$ & 120 & 9-20\% weight reduction & Kyaw et al., 2012 \\
\hline Rhodococcus ruber & PE waste soil & LDPE & $20-28$ & $0.8-8 \%$ weight reduction & Orr et al., 2004 \\
\hline $\begin{array}{l}\text { Rhodococcus } \\
\text { rhorocuros }\end{array}$ & Soil & $\mathrm{PE}$ & 180 & $60 \%$ mineralization & Bonhomme et al., 2003 \\
\hline Rhodococcus sp. & Waste disposal site & Pretreated PE & 21 & $33 \%$ weight reduction & Koutny et al., 2009 \\
\hline Streptomyces sp. & River delta & Pretreated PE bags & 30 & slight weight reduction & El-Shafei et al., 1998 \\
\hline $\begin{array}{l}\text { Staphylococcus } \\
\text { arlettae }\end{array}$ & Soil & $\mathrm{PE}$ & 30 & $13.6 \%$ weight reduction & $\begin{array}{l}\text { Divyalakshmi and } \\
\text { Subhashini, } 2016\end{array}$ \\
\hline Bacillus sp. & Waste coal & $\mathrm{PE}$ & 225 & $98 \%$ weight reduction & Nowak et al., 2011 \\
\hline Bacillus sphaericus & Shallow ocean water & HDPE/LDPE & 365 & $3.5-10 \%$ & Sudhakar et al., 2008 \\
\hline Bacillus megaterium & Soil & Pretreated PE & 90 & 7-10\% mineralization & Abrusci et al., 2011 \\
\hline $\begin{array}{l}\text { Bacillus } \\
\text { amyloliquefaciens }\end{array}$ & Solid waste dump site & LDPE & 60 & $11-16 \%$ weight reduction & Das and Kumar, 2015 \\
\hline Bacillus subtilis $\mathrm{H} 1584$ & Pelagic waters & PE & 30 & $1.5-1.75 \%$ weight reduction & $\begin{array}{l}\text { Harshvardhan and Jha, } \\
2013\end{array}$ \\
\hline $\begin{array}{l}\text { Chryseobacterium } \\
\text { gleum }\end{array}$ & Activated sludge & UV irradiated LPDPE & 30 & Chemical alteration & Jeon and Kim, 2014 \\
\hline
\end{tabular}

the evidences of changes in surface morphology and chemical modifications by AFM, SEM and FTIR. Both, AFM and SEM analyses confirmed significant modifications on the surface of LDPE films and weakening of their physical integrity due to microbial action by both the strains (Li et al., 2020). Apart from the visible modifications, almost 2-3 fold increase in nanoroughness parameters namely $\mathrm{Ra}, \mathrm{Rv}, \mathrm{Rp}, \mathrm{Rq}$, and $\mathrm{Rz}$ added stronger evidence to the alteration of roughness of the films because of microbial action. Higher values of $\mathrm{Rz}$, which is the maximum height, suggested toward the presence of big grooves and pits (Peixoto et al., 2017). All the changes also indicated toward the penetration of the bacterial cells into the LDPE film surface (Esmaeili et al., 2013). These results indicated that the LDPE degradation had been initiated by the plastic degrading strains due to their enzymatic action, where laccase, esterase, mono-oxygenase, peroxidases might play significant role (Ahmed et al., 2018; Ru et al., 2020). In order to support these results, chemical modifications of the LDPE films were determined by FTIR. Chemical modification reflected the change in carbon backbone and helped to understand the 


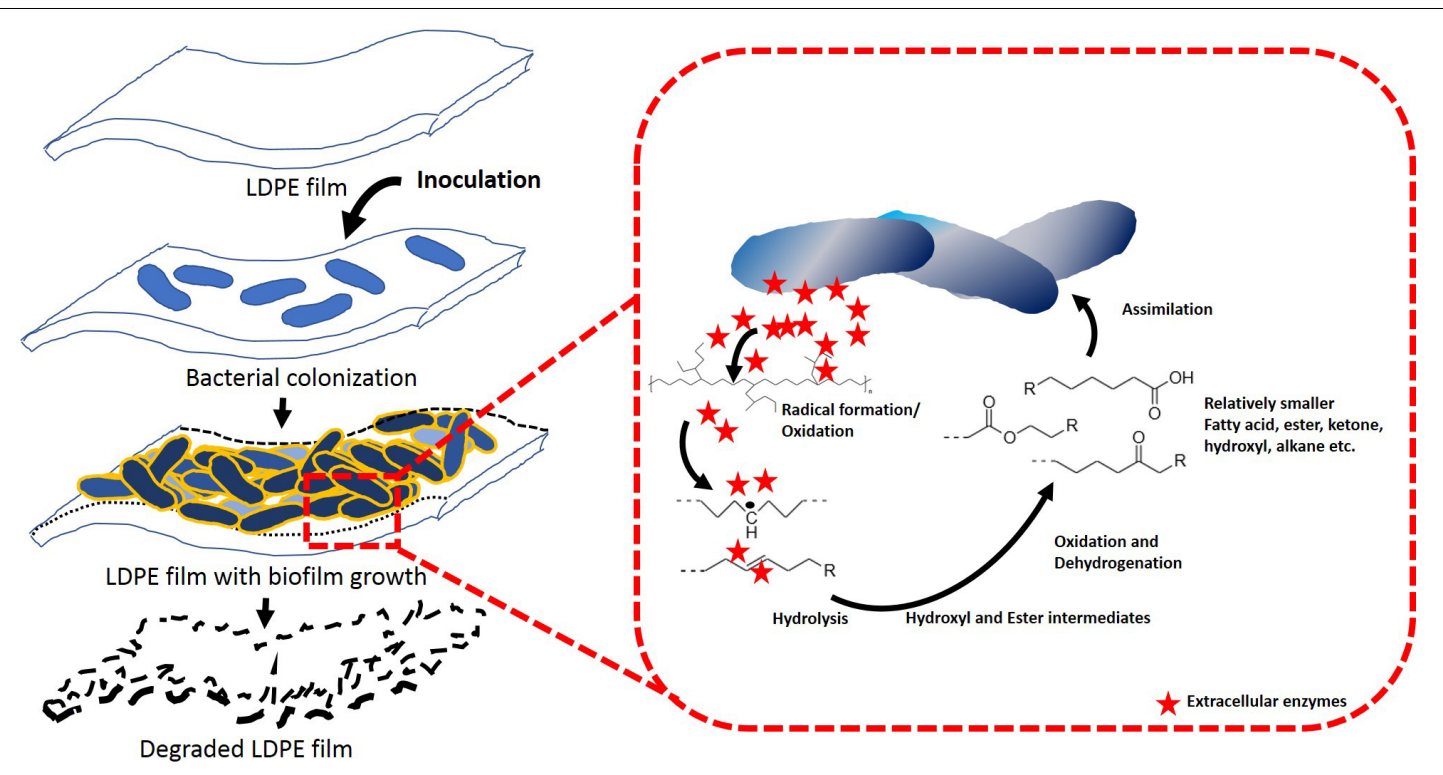

FIGURE 6 | Proposed LDPE degradation mechanism by Stenotrophomonas sp. P2 and Achromobacter sp. DF22.

formation of functional groups on LDPE or any molecule formed during the degradation process. FTIR spectroscopy is widely used as an efficient analytical technique to identify organic, polymeric and inorganic material and their chemical conformation. This technique had been utilized in earlier studies to display the chemical changes during plastic biodegradation (Peixoto et al., 2017; Montazer et al., 2018; Li et al., 2020). New functional groups (such as alkoxy, acyl, carbonyl, and nitro) were found and modifications in terms of chain scissioning, nitro stretching and double bond formation took place. Thus, the hydrophobicity of inert LDPE was reduced due to the incorporation of functional bonds to facilitate the microbial action. Although the exact enzymatic reactions are yet to be understood, the overall process of biodegradation and enzymatic mechanism could be conceptualized from the FTIR analysis (Figure 6). Together from the increased indices (CI, DBI, TDBI) and the spectral analysis it could be inferred that the degradation process might have been initiated by the formation of radicals that helped in enhancing oxidation with the help of oxygen and water. These oxidation products were then transformed to the functional groups and vinylene group probably by Norrish type I and Norrish type II mechanisms or stabilization. Thus, the hydrophobicity of the plastic surface was reduced so that the subsequent bacterial enzymes could enhance the degradation process. Presence of alkoxy and acyl groups in the treated samples indicated ester hydrolysis and alcohol formation due to the action of microbial hydrolytic enzymes such as cutinase, lipase, esterase and alkane monooxygenase. Formation of carbonyl bonds could have occurred due to the action of laccase. These ester, alcohol, etc., could be subsequently converted to smaller fatty acids through an intermediate step of aldehyde production by dehydrogenase enzymes. Thus, smaller molecular products were formed and could be taken up by the bacteria for metabolism, leading to mineralization via $\beta$-oxidation (Ogihara, 1963; Albertsson et al., 1987; Orr et al.,
2004; Szép et al., 2004; Chatterjee et al., 2010; Peixoto et al., 2017; Ru et al., 2020). These processes resulted in the breaking down of LDPE films causing the surface changes on the films.

\section{CONCLUSION}

This study displayed the LDPE biodegradation potential of microbial consortium enriched (using LDPE as sole carbon source) from dumpsite and drilling fluids and the bacterial strains isolated from these enrichments. Significant microbial growth, high cell surface hydrophobicity of the enriched consortia and considerable weight reduction of treated LDPEs gave a primary indication of the biodegradation capacity of the enriched consortia. Two LDPE degrading bacterial strains affiliated to Stenotrophomonas sp. and Achromobacter sp. were isolated as pure culture from P and DF2 enrichments. SEM and AFM analyses confirmed that both the strains were successful in altering the cell surface morphology of the LDPE beads. The overview of possible mechanism of LDPE biodegradation by these two strains was also established in this study. FTIR analysis suggested that series of chemical changes starting from oxidation followed by dehydrogenation led to the breaking down of LDPE into smaller molecules, which could be subsequently utilized by these two strains for their metabolism. Complete microbial composition of the enrichments can be analyzed through next generation sequencing based approach and would help us to identify the complex network of biological systems involved in LDPE degradation. This would enable us to develop a stable microbial consortium capable of LDPE degradation, which could be utilized for large-scale biodegradation of plastic. Further investigation on the metabolic pathways, enzymatic reactions and metabolites would help us understanding the exact mechanism of biodegradation by these bacterial strains to develop in situ process for LDPE biodegradation. 


\section{DATA AVAILABILITY STATEMENT}

The datasets presented in this study can be found in online repositories. The names of the repository/repositories and accession number(s) can be found in the article/ supplementary material.

\section{AUTHOR CONTRIBUTIONS}

$\mathrm{AD}$ performed the experiments, analyzed the data, and drafted the manuscript. HB helped with the phylogenetic analysis and manuscript preparation. BM helped in analytical methods and data analysis. PS conceived the idea, arranged funds, supervised all the experiments, data analysis, and manuscript writing. All authors contributed to the article and approved the submitted version.

\section{REFERENCES}

Abe, M., Kobayashi, K., Honma, N., and Nakasaki, K. (2010). Microbial degradation of poly (butylene succinate) by Fusarium solani in soil environments. Polym. Degrad. Stab. 95, 138-143. doi: 10.1016/j. polymdegradstab.2009.11.042

Abraham, J., Ghosh, E., Mukherjee, P., and Gajendiran, A. (2017). Microbial degradation of low density polyethylene. Environ. Prog. Sustain. Energy 36, 147-154. doi: 10.1002/ep.12467

Abrusci, C., Pablos, J. L., Corrales, T., López-Marín, J., Marín, I., and Catalina, F. (2011). Biodegradation of photo-degraded mulching films based on polyethylenes and stearates of calcium and iron as pro-oxidant additives. Int. Biodeterior. Biodegradation 65, 451-459. doi: 10.1016/j.ibiod.2010.10.012

Ahmed, T., Shahid, M., Azeem, F., Rasul, I., Shah, A. A., Noman, M., et al. (2018). Biodegradation of plastics: current scenario and future prospects for environmental safety. Environ. Sci. Pollut. Res. 25, 7287-7298. doi: 10.1007/ s11356-018-1234-9

Albertsson, A. C., Andersson, S. O., and Karlsson, S. (1987). The mechanism of biodegradation of polyethylene. Polym. Degrad. Stab. 18, 73-87. doi: 10.1016/ 0141-3910(87)90084-X

Albertsson, A. C., and Karlsson, S. (1990). The influence of biotic and abiotic environments on the degradation of polyethylene. Prog. Polym. Sci. 15, 177-192. doi: 10.1016/0079-6700(90)90027-X

Alekhina, I. A., Marie, D., Petit, J. R., Lukin, V. V., Zubkov, V. M., and Bulat, S. A. (2007). Molecular analysis of bacterial diversity in kerosene-based drilling fluid from the deep ice borehole at Vostok, East Antarctica. FEMS Microbiol. Ecol. 59, 289-299. doi: 10.1111/j.1574-6941.2006.00271.x

Andrady, A. L., and Neal, M. A. (2009). Applications and societal benefits of plastics. Philos. Trans. R. Soc. B Biol. Sci. 364, 1977-1984. doi: 10.1098/rstb.2008. 0304

Bhardwaj, H., Gupta, R., and Tiwari, A. (2013). Communities of microbial enzymes associated with biodegradation of plastics. J. Polym. Environ. 21, 575-579. doi: 10.1007/s10924-012-0456-z

Bhatia, M., Girdhar, A., Tiwari, A., and Nayarisseri, A. (2014). Implications of a novel Pseudomonas species on low density polyethylene biodegradation: an in vitro to in silico approach. Springerplus 3:497. doi: 10.1186/2193-18013-497

Bonhomme, S., Cuer, A., Delort, A. M., Lemaire, J., Sancelme, M., and Scott, G. (2003). Environmental biodegradation of polyethylene. Polym. Degrad. Stab. 81, $441-452$.

Bose, H., Dutta, A., Roy, A., Gupta, A., Mukhopadhyay, S., Mohapatra, B., et al. (2020). Microbial diversity of drilling fluids from $3000 \mathrm{~m}$ deep Koyna pilot borehole provides insights into the deep biosphere of continental earth crust. Sci. Dril. 27, 1-23. doi: 10.5194/sd-27-1-2020

\section{ACKNOWLEDGMENTS}

Authors acknowledge the analytical instrument facility provided by Central Research Facility, IIT Kharagpur for their assistance in SEM, AFM, and FTIR analyses. The authors wish to thank Prof. Santanu Chattopadhyay (Department of Rubber Technology, IIT Kharagpur) for his suggestions and help in the study. AD gratefully acknowledges the MHRD fellowship provided by IIT Kharagpur. HB is a recipient of National Post-Doctoral Fellowship (PDF/2017/000657) from Department of Science and Technology, Government of India. BM is a recipient of an Inspire Fellowship from the Department of Science and Technology, Government of India. Authors acknowledge the kind support received from Borehole Geophysics Research Laboratory, Karad and Ministry of Earth Sciences, Government of India for collecting the drilling fluids from the Koyna Pilot bore hole drilling.

Chatterjee, S., Roy, B., Roy, D., and Banerjee, R. (2010). Enzyme-mediated biodegradation of heat treated commercial polyethylene by Staphylococcal species. Polym. Degrad. Stab. 95, 195-200. doi: 10.1016/j.polymdegradstab.2009. 11.025

Chen, S., Yang, L., Hu, M., and Liu, J. (2011). Biodegradation of fenvalerate and 3-phenoxybenzoic acid by a novel Stenotrophomonas sp. strain ZS-S-01 and its use in bioremediation of contaminated soils. Appl. Microbiol. Biotechnol. 90, 755-767. doi: 10.1007/s00253-010-3035-Z

Danso, D., Chow, J., and Streit, W. R. (2019). Plastics: environmental and biotechnological perspectives on microbial degradation. Appl. Environ. Microbiol. 85:e01095-19. doi: 10.1128/AEM.01095-19

Das, G., Bordoloi, N. K., Rai, S. K., Mukherjee, A. K., and Karak, N. (2012). Biodegradable and biocompatible epoxidized vegetable oil modified thermostable poly (vinyl chloride): thermal and performance characteristics post biodegradation with Pseudomonas aeruginosa and Achromobacter sp. J. Hazard. Mater. 209-210, 434-442. doi: 10.1016/j.jhazmat.2012.01.043

Das, M. P., and Kumar, S. (2015). An approach to low-density polyethylene biodegradation by Bacillus amyloliquefaciens. 3 Biotech 5, 81-86. doi: 10.1007/ s13205-014-0205-1

Delacuvellerie, A., Cyriaque, V., Gobert, S., Benali, S., and Wattiez, R. (2019). The plastisphere in marine ecosystem hosts potential specific microbial degraders including Alcanivorax borkumensis as a key player for the low-density polyethylene degradation. J. Hazard. Mater. 380:120899. doi: 10.1016/j.jhazmat. 2019.120899

Divyalakshmi, S., and Subhashini, A. (2016). Screening and isolation of polyethylene degrading bacteria from various soil environments. IOSR J. Environ. Sci. Toxicol. Food Technol. 10, 1-7. doi: 10.9790/2402-1012040107

Duddu, M. K., Tripura, K. L., Guntuku, G., and Divya, D. S. (2015). Biodegradation of low density polyethylene (LDPE) by a new biosurfactant-producing thermophilic Streptomyces coelicoflavus NBRC 15399T. Afr. J. Biotechnol. 14, 327-340. doi: 10.5897/AJB2014.14224

El-Shafei, H., Ei-Nasser, N. H. A., Kansoh, A. L., and Ali, A. M. (1998). Biodegradation of disposable polyethylene by fungi and Streptomyces species. Polym. Degrad. Stab. 62, 361-365. doi: 10.1016/S0141-3910(98)00019-6

Esmaeili, A., Pourbabaee, A. A., Alikhani, H. A., Shabani, F., and Esmaeili, E. (2013). Biodegradation of low-density polyethylene (LDPE) by mixed culture of Lysinibacillus xylanilyticus and Aspergillus niger in soil. PLoS One 8:e71720. doi: 10.1371/journal.pone.0071720

Fei, Y., Huang, S., Zhang, H., Tong, Y., Wen, D., Xia, X., et al. (2020). Response of soil enzyme activities and bacterial communities to the accumulation of microplastics in an acid cropped soil. Sci. Total Environ. 707:135634. doi: 10. 1016/j.scitotenv.2019.135634

Felsenstein, J. (1981). Evolutionary trees from DNA sequences: a maximum likelihood approach. J. Mol. Evol. 17, 368-376. doi: 10.1007/bf01734359 
Gajendiran, A., Krishnamoorthy, S., and Abraham, J. (2016). Microbial degradation of low-density polyethylene (LDPE) by Aspergillus clavatus strain JASK1 isolated from landfill soil. 3 Biotech 6:52. doi: 10.1007/s13205-0160394-X

Hadad, D., Geresh, S., and Sivan, A. (2005). Biodegradation of polyethylene by the thermophilic bacterium Brevibacillus borstelensis. J. Appl. Microbiol. 98, 1093-1100. doi: 10.1111/j.1365-2672.2005.02553.x

Harshvardhan, K., and Jha, B. (2013). Biodegradation of low-density polyethylene by marine bacteria from pelagic waters, Arabian Sea, India. Mar. Pollut. Bull. 77, 100-106. doi: 10.1016/j.marpolbul.2013.10.025

Huang, Y., Zhao, Y., Wang, J., Zhang, M., Jia, W., and Qin, X. (2019). LDPE microplastic films alter microbial community composition and enzymatic activities in soil. Environ. Pollut. 254(Pt A):112983. doi: 10.1016/j.envpol.2019. 112983

Jeon, H. J., and Kim, M. N. (2014). Degradation of linear low density polyethylene (LLDPE) exposed to UV-irradiation. Eur. Polym. J. 52, 146-153. doi: 10.1016/j. eurpolymj.2014.01.007

Jeon, H. J., and Kim, M. N. (2015). Functional analysis of alkane hydroxylase system derived from Pseudomonas aeruginosa E7 for low molecular weight polyethylene biodegradation. Int. Biodeterior. Biodegradation 103, 141-146. doi: 10.1016/j.ibiod.2015.04.024

Jukes, T. H., and Cantor, C. R. (1969). "Evolution of protein molecules," in Mammalian Protein Metabolism, ed. H. N. Munro (New York, NY: Academic Press), 132.

Karamanlioglu, M., Preziosi, R., and Robson, G. D. (2017). The compostable plastic poly (lactic) acid causes a temporal shift in fungal communities in maturing compost. Compost Sci. Util. 25, 211-219. doi: 10.1080/1065657X.2016.1277808

Kathiresan, K. (2003). Polythene and plastics-degrading microbes from the mangrove soil. Rev. Biol. Trop. 51, 629-633.

Kim, M., Oh, H. S., Park, S. C., and Chun, J. (2014). Towards a taxonomic coherence between average nucleotide identity and 16S rRNA gene sequence similarity for species demarcation of prokaryotes. Int. J. Syst. Evol. Microbiol. 64(Pt 2), 346-351. doi: 10.1099/ijs.0.059774-0

Koutny, M., Amato, P., Muchova, M., Ruzicka, J., and Delort, A. M. (2009). Soil bacterial strains able to grow on the surface of oxidized polyethylene film containing prooxidant additives. Int. Biodeterior. Biodegradation 63, 354-357. doi: 10.1016/j.ibiod.2008.11.003

Kowalczyk, A., Chyc, M., Ryszka, P., and Latowski, D. (2016). Achromobacter xylosoxidans as a new microorganism strain colonizing high-density polyethylene as a key step to its biodegradation. Environ. Sci. Pollut. Res. 23, 11349-11356. doi: 10.1007/s11356-016-6563-y

Kumar, S., Stecher, G., Li, M., Knyaz, C., and Tamura, K. (2018). MEGA X: molecular evolutionary genetics analysis across computing platforms. Mol. Biol. Evol. 35, 1547-1549. doi: 10.1093/molbev/msy096

Kyaw, B. M., Champakalakshmi, R., Sakharkar, M. K., Lim, C. S., and Sakharkar, K. R. (2012). Biodegradation of low density polythene (LDPE) by Pseudomonas species. Indian J. Microbiol. 52, 411-419. doi: 10.1007/s12088-0120250-6

Lee, B., Pometto, A. L., Fratzke, A., and Bailey, T. B. (1991). Biodegradation of degradable plastic polyethylene by Phanerochaete and Streptomyces species. Appl. Environ. Microbiol. 57, 678-685. doi: 10.1128/aem.57.3.678-685.1991

Li, Z., Wei, R., Gao, M., Ren, Y., Yu, B., Nie, K., et al. (2020). Biodegradation of lowdensity polyethylene by Microbulbifer hydrolyticus IRE-31. J. Environ. Manage. 263:110402. doi: 10.1016/j.jenvman.2020.110402

Manijeh, M., Mohammad, J., and Roha, K. K. (2008). Biofilm formation by Salmonella enteritidis on food contact surfaces. J. Biol. Sci. 8, 502-505. doi: $10.3923 /$ jbs.2008.502.505

Mehmood, C. T., Qazi, I. A., Hashmi, I., Bhargava, S., and Deepa, S. (2016). Biodegradation of low density polyethylene (LDPE) modified with dye sensitized titania and starch blend using Stenotrophomonas pavanii. Int. Biodeter. Biodegradation 113, 276-286. doi: 10.1016/j.ibiod.2016.01.025

Mohapatra, B., Sar, P., Kazy, S. K., Maiti, M. K., and Satyanarayana, T. (2018). Taxonomy and physiology of Pseudoxanthomonas arseniciresistens sp. nov., an arsenate and nitrate-reducing novel gammaproteobacterium from arsenic contaminated groundwater, India. PLoS One 13:e0193718. doi: 10.1371/journal. pone. 0193718

Montazer, Z., Habibi-Najafi, M. B., Mohebbi, M., and Oromiehei, A. (2018). Microbial degradation of UV-pretreated low-density polyethylene films by novel polyethylene-degrading bacteria isolated from plastic-dump soil. J. Polym. Environ. 26, 3613-3625. doi: 10.1007/s10924-018-1245-0

Muhonja, C. N., Makonde, H., Magoma, G., and Imbuga, M. (2018). Biodegradability of polyethylene by bacteria and fungi from Dandora dumpsite Nairobi-Kenya. PLoS One 13:e0198446. doi: 10.1371/journal.pone.01 98446

Nowak, B., Pajak, J., Drozd-Bratkowicz, M., and Rymarz, G. (2011). Microorganisms participating in the biodegradation of modified polyethylene films in different soils under laboratory conditions. Int. Biodeterior. Biodegradation 65, 757-767. doi: 10.1016/j.ibiod.2011.04.007

Ogihara, T. (1963). Oxidative degradation of polyethylene in nitrogen dioxide. Bull. Chem. Soc. Jpn. 36, 58-63. doi: 10.1246/bcsj.36.58

Orr, I. G., Hadar, Y., and Sivan, A. (2004). Colonization, biofilm formation and biodegradation of polyethylene by a strain of Rhodococcus ruber. Appl. Microbiol. Biotechnol. 65, 97-104. doi: 10.1007/s00253-004-1584-8

Ozyurek, S. B., and Bilkay, I. S. (2017). Determination of petroleum biodegradation by bacteria isolated from drilling fluid, waste mud pit and crude oil. Turk. J. Biochem. 42, 609-616. doi: 10.1515/tjb-2017-0087

Ozyurek, S. B., and Bilkay, I. S. (2018). Biodegradation of petroleum by Klebsiella pneumoniae isolated from drilling fluid. Int. J. Environ. Sci. Technol. 15, 21072116. doi: 10.1007/s13762-017-1581-y

Papizadeh, M., Ardakani, M. R., Motamedi, H., Rasouli, I., and Zarei, M. (2011). C-S targeted biodegradation of dibenzothiophene by Stenotrophomonas sp. NISOC-04. Appl. Biochem. Biotechnol. 165, 938-948. doi: 10.1007/s12010-0119310-3

Park, S. Y., and Kim, C. G. (2019). Biodegradation of micro-polyethylene particles by bacterial colonization of a mixed microbial consortium isolated from a landfill site. Chemosphere 222, 527-533. doi: 10.1016/j.chemosphere.2019. 01.159

Peixoto, J., Silva, L. P., and Krüger, R. H. (2017). Brazilian Cerrado soil reveals an untapped microbial potential for unpretreated polyethylene biodegradation. J. Hazard. Mater. 324( $\mathrm{Pt}$ B), 634-644. doi: 10.1016/j.jhazmat.2016. 11.037

Pramila, R., and Ramesh, K. V. (2015). Potential biodegradation of low density polyethylene (LDPE) by Acinetobacter baumannii. J. Bacteriol. Res. 7, 24-28. doi: $10.5897 / J B R 2015.0152$

Raddadi, N., and Fava, F. (2019). Biodegradation of oil-based plastics in the environment: existing knowledge and needs of research and innovation. Sci. Total Environ. 679, 148-158. doi: 10.1016/j.scitotenv.2019.04.419

Rajandas, H., Parimannan, S., Sathasivam, K., Ravichandran, M., and Yin, L. S. (2012). A novel FTIR-ATR spectroscopy based technique for the estimation of low-density polyethylene biodegradation. Polym. Test. 31, 1094-1099. doi: 10.1016/j.polymertesting.2012.07.015

Rosenberg, M., Gutnick, D., and Rosenberg, E. (1980). Adherence of bacteria to hydrocarbons: a simple method for measuring cell-surface hydrophobicity. FEMS Microbiol. Lett. 9, 29-33. doi: 10.1111/j.1574-6968.1980.tb05599.x

Roy, S., and Bansal, B. (2020). Government of India, Ministry of earth sciencesBorehole Geophysics Research Laboratory, Karad, Maharashtra. Proc. Indian Natl. Sci. Acad. 86, 759-767. doi: 10.16943/ptinsa/2020/49825

Ru, J., Huo, Y., and Yang, Y. (2020). Microbial degradation and valorization of plastic wastes. Front. Microbiol. 11:442. doi: 10.3389/fmicb.2020.00442

Saitou, N., and Nei, M. (1987). The neighbor-joining method: a new method for reconstructing phylogenetic trees. Mol. Biol. Evol. 4, 406-425. doi: 10.1093/ oxfordjournals.molbev.a040454

Sanin, S. L., Sanin, F. D., and Bryers, J. D. (2003). Effect of starvation on the adhesive properties of xenobiotic degrading bacteria. Process Biochem. 38, 909-914. doi: 10.1016/S0032-9592(02)00173-5

Sarker, R. K., Chakraborty, P., Paul, P., Chatterjee, A., and Tribedi, P. (2020). Degradation of low-density poly ethylene (LDPE) by Enterobacter cloacae AKS7: a potential step towards sustainable environmental remediation. Arch. Microbiol. 202, 2117-2125. doi: 10.1007/s00203-020-01926-8

Sivan, A. (2011). New perspectives in plastic biodegradation. Curr. Opin. Biotech. 22, 422-426. doi: 10.1016/j.copbio.2011.01.013

Sivan, A., Szanto, M., and Pavlov, V. (2006). Biofilm development of the polyethylene-degrading bacterium Rhodococcus ruber. Appl. Microbiol. Biotechnol. 72, 346-352. doi: 10.1007/s00253-005-0259-4

Soulenthone, P., Tachibana, Y., Muroi, F., Suzuki, M., Ishii, N., Ohta, Y., et al. (2020). Characterization of a mesophilic actinobacteria that degrades poly 
(butylene adipate-co-terephthalate). Polym. Degrad. Stab. 181:109335. doi: 10. 1016/j.polymdegradstab.2020.109335

Sudhakar, M., Doble, M., Murthy, P. S., and Venkatesan, R. (2008). Marine microbe-mediated biodegradation of low-and high-density polyethylenes. Int. Biodeter. Biodegradation 61, 203-213. doi: 10.1016/j.ibiod.2007.07.011

Szép, A., Anna, P., Csontos, I., Marosi, G., Matko, S., and Bertalan, G. (2004). Micro Raman and atomic force microscopy analysis of naturally aged polyethylene. Polym. Degrad. Stab. 85, 1023-1027. doi: 10.1016/j.polymdegradstab.2003. 05.004

Takahashi, K., and Nei, M. (2000). Efficiencies of fast algorithms of phylogenetic inference under the criteria of maximum parsimony, minimum evolution, and maximum likelihood when a large number of sequences are used. Mol. Biol. Evol. 17, 1251-1258. doi: 10.1093/oxfordjournals.molbev.a02 6408

Teuten, E. L., Saquing, J. M., Knappe, D. R., Barlaz, M. A., Jonsson, S., Björn, A., et al. (2009). Transport and release of chemicals from plastics to the environment and to wildlife. Philos. Trans. R. Soc. Lond. B Biol. Sci. 364, 2027-2045. doi: 10.1098/rstb.2008.0284

Tokiwa, Y., Calabia, B. P., Ugwu, C. U., and Aiba, S. (2009). Biodegradability of plastics. Int. J. Mol. Sci. 10, 3722-3742. doi: 10.3390/ijms10093722

Tribedi, P., and Sil, A. K. (2013). Low-density polyethylene degradation by Pseudomonas sp. AKS2 biofilm. Environ. Sci. Pollut. Res. 20, 4146-4153. doi: 10.1007/s11356-012-1378-y

Usha, R., Sangeetha, T., and Palaniswamy, M. (2011). Screening of polyethylene degrading microorganisms from garbage soil. Libyan Agric. Res. Cent. J. Int. 2, 200-204.
Wei, R., and Zimmermann, W. (2017). Microbial enzymes for the recycling of recalcitrant petroleum-based plastics: how far are we? Microb. Biotechnol. 10, 1308-1322. doi: 10.1111/1751-7915.12710

Wilkes, R. A., and Aristilde, L. (2017). Degradation and metabolism of synthetic plastics and associated products by Pseudomonas sp.: capabilities and challenges. J. Appl. Microbiol. 123, 582-593. doi: 10.1111/jam.13472

Yang, J., Yang, Y., Wu, W. M., Zhao, J., and Jiang, L. (2014). Evidence of polyethylene biodegradation by bacterial strains from the guts of plastic-eating waxworms. Environ. Sci. Technol. 48, 13776-13784. doi: 10.1021/es504038a

Yoon, M. G., Jeon, H. J., and Kim, M. N. (2012). Biodegradation of polyethylene by a soil bacterium and AlkB cloned recombinant cell. J. Bioremediat. Biodegradation 3, 1-8. doi: 10.4172/2155-6199.1000145

Yuan, J., Ma, J., Sun, Y., Zhou, T., Zhao, Y., and Yu, F. (2020). Microbial degradation and other environmental aspects of microplastics/plastics. Sci. Total Environ. 715:136968. doi: 10.1016/j.scitotenv.2020.136968

Conflict of Interest: The authors declare that the research was conducted in the absence of any commercial or financial relationships that could be construed as a potential conflict of interest.

Copyright (c) 2020 Dey, Bose, Mohapatra and Sar. This is an open-access article distributed under the terms of the Creative Commons Attribution License (CC BY). The use, distribution or reproduction in other forums is permitted, provided the original author(s) and the copyright owner(s) are credited and that the original publication in this journal is cited, in accordance with accepted academic practice. No use, distribution or reproduction is permitted which does not comply with these terms. 